\title{
HOW MEN CAN SHAPE THEIR FUTURE
}

John Platt

A 'wagon-train model' of pioneers moving into unknown country helps to illuminate the collective cybernetics of social goal-seeking and social change. The future is divided into an inertia period (of 2-10 years?), $T_{\mathrm{I}}$, followed by a choice-and-control period (of 10-20 years?), $T_{\mathrm{C}}$, followed by the uncertain future, $T_{\mathrm{U}}$. In the historical process of leadership and collective decision for the $T_{\mathrm{C}}$ period, maps of alternatives with costs and benefits ('contour maps') are seen as important power sources and conflict reducers.

The Protestant theologian, Harvey Cox, has a recent book entitled, On No Leaving It To The Snake. It is a plea for mankind to take responsibility for the world and its future. The whimsical title is derived from the situation in the Garden of Eden. Adam and Eve had been given dominion over all the animals in the Garden but, as Cox says, when they came to the moment of truth, they let the snake decide.

Today this is no longer a parable of the past but of the present. Mankind now has the technological power to make the world a Garden of Eden, a Garden of abundance. And with our poisons and our protection, we now have dominion over the numbers of all the plants and animals in this Garden, including ourselves. In this analogy, some might identify the snake with our ancient habits and attitudes and our failure to control population or human conflict. But the real snake in the Garden today is our misunderstanding of human history and human responsibility.

As Cox goes on to say, there are three major attitudes towards history. The first is the apocalyptic attitude, that the human race is doomed. The second is the chiliastic or Messianic attitude, that it is destined to a glorious future. In many of us there still lurk these or some other deterministic variations,

John Platt is a research biophysicist and Associate Director of the Mental Health Research Institute at the University of Michigan, USA. This paper was given at the International Futures Research Conference in Kyoto, April 1970. 
such as the view that history is random or that it is cyclical or that it is determined by economic or technological imperatives or innate human aggression, so that in any case there is nothing we can do about it.

Against all these, however, Cox would set the third attitude, which he calls the prophetic attitude towards history, and which he identifies with the attitudes of the prophets of the Old and New Testaments. They held that history is conditional, that is, that it is an 'if ...then ...' process, with the future shaped by what we choose and do. If you steal or kill or bear false witness, then you will roast in hell. If you love God with all your heart, then you begin to create around you the Kingdom of Heaven.

\section{Guiding the wagon train of history}

This comes close to the existentialist view which sees the future as continually being shaped by human responsibility and action. Indeed, the if-then view is the view we take every day as we plan supper or a vacation trip or a career. Nations plan social security and economic development. Why should it seem so hopeless to plan or shape a world? The reason is that in the past, with warring nations and uncertain catastrophes, we had to leave it up to God or chance to determine the large-scale future. Random surprises, or statistical stabilisation, or the feedback stabilisation of the Invisible Hand of the market-place, or selfstabilising attitudes or organisational structures, were likely to thwart any deliberate plan. But today we are beginning to have the world organisation and the technological power and understanding to actually achieve some successes in large-scale planning.

As we do so, we begin to need a coherent picture of the process of social design and change. Social processes should no longer be compared to a railroad train running on fixed tracks to an inevitable destination, but rather to a wagon train of settlers moving across the country towards the frontier, in an on-going collective search for a better place to live.

It is worth exploring this last simile in some detail. For example, it is certainly true that for any well-organised living organism, or decision-system, or social group, the process of change is in many ways like the driving of a single vehicle. At a given instant of time, a vehicle-or a society-is at a particular place with a particular direction of motion determined by its previous history. (Initial position, $x$, and velocity, $\dot{x}$, as the physicists would say.) For some short time ahead, which we might call the correlation-time or the inertia-time, $T_{\mathrm{I}}$, little can be done to change its course. We hit the dog on the road, or our society gets into the war, regardless of the most heroic efforts to swerve away. This interval goes over gradually into a second time period, the choice-period, $T_{\mathrm{C}}$, within which our present steering will be increasingly effective in avoiding danger or achieving an intended path or goal. (In physics, our deliberately chosen steering force of acceleration, $\ddot{x}$, now as we turn the wheel, will finally produce a calculated change of time-course or path.) This interval finally goes over into a third period, $T_{\mathrm{U}}$, the time-period of uncertainty, which is too far off and too dependent on intervening hazards and our intervening responses, for present planning or steering to be relevant except in terms of very general directions. (The ' $I-C-U$ ' model.) 


\section{The periods of prediction and choice}

The three periods are not sharply separated, and of course their lengths may be different for different social phenomena. Nevertheless, the relation of prediction, choice, and planning, is very different for the three intervals. In the first period or inertia-period, $T_{\mathrm{I}}$, social science is deterministic like the natural sciences, because non-interfering predictions or extrapolations are possible, to the extent that the causal chains in society are understood. The predictions of course are not necessarily linear, and they may have oscillations or exponential explosions or decays. And they may be probabilistic and uncertain because of extra-societal intrusions (like assassinations or external attacks), thus resembling probabilistic predictions in physics.

But the whole nature of prediction changes for the second period ahead, $T_{\mathrm{C}}$, which is governed not by physics but by cybernetics. Thus, in driving a vehicle, the momentum-physics of the next half-second from now is steadily replaced, in anticipating future seconds, by the cybernetics of goal-directed steering. The 'weak interactions' of the natural sciences, where the observer or his prediction does not change the phenomenon, become replaced by the 'strong interactions' of organism-environment feedbacks, where prediction changes to a range of alternatives with cybernetic choice. It ceases to be prediction and becomes 'prophecy' in the sense used by Harvey Cox. It becomes 'if-then' prophecy, which does not tell us what will happen, but rather what is the range of directions we can go in, and where we will go if we turn the wheel of initiating-action by a particular amount one way or the other. 'Predictions' cease to be predictions and become something more like 'advice' or 'warnings' so that the alert society, or the alert driver, can avoid the foreseen dangers or choose the desirable directions that have just become apparent. For this period, the problem is not to predict the future but to change it.

It is sometimes supposed that these choices by a driver or a group of drivers as they scan the alternatives, are themselves predictable by psychology or social science. This, however, is false, since science is a public affair, and if the social scientist is a responsible and participating human being, he will surely communicate his forecasts of great opportunities or great dangers, and he will thus become an interacting part of the decision system. All social science 'predictions' of such decisions therefore begin to share the logical fallacy of 'self-predictions', which are not predictions at all but cybernetic intentions or warnings, with uncertain outcomes depending on the resultant choice and action. (Thus, in economics, the notorious unpredictability of the stock market may be a simple result of the strong short-time interaction between 'predictions'-which are warnings-and decisions, with group effects and leader effects preventing even a statistical stabilisation.) The final choice and action after such 'predictions', are certainly not predictable from any simplistic or 'rational' assumptions. We, or our leaders or protesters, will often insinuate amplified fluctuations in our value-systems, for the most personal and subtle of reasons-so that instead of choosing the easiest or the shortest path towards a goal, we often choose a different one for aesthetic reasons or for exploration or to test ourselves or just for the sake of variety.

When we look at the $T_{\mathrm{I}}$ and the $T_{\mathrm{C}}$ periods in this way, we see therefore that 
we must distinguish something like five futurist categories: predictions, uncertain predictions, prophecies (or ranges of alternatives), intentions, and interacting decision-making. These distinctions give us a new view of our controversies about the 'descriptive' or 'normative' character of the social sciences, and about their ultimate ability to make accurate predictions as in the physical sciences. These disputes are the result of a failure to separate prediction and choice in the different time-periods of reference, coupled with a widespread failure to appreciate the cybernetic character of well-organised social dynamics. The dynamics of society and social change, as we see here, is rooted not primarily in the physical sciences, but rather in the organism-environment cybernetic interactions characteristic of the biological sciences.

The third future period, the ultimate period of uncertainty, $\mathcal{T}_{U}$, is like the period after the next bend in the road. It is a period for which only general goals - or the preparation for general goals-can be chosen now, and the details of the path have to be worked out as we come closer and can see better. This is a period for which, because of our inability to see details, our present choices often can be guided only by some very general heuristics or values or moral rules that have worked in the past, or by some kind of Sitzgefühl as in chess. When the uncertainties are great, as in times of war or revolution, the $T_{U}$ period comes very close to us, a day or an hour away, and the moral rules shift towards the necessities of immediate survival, so that a man is a fool if he starts building a house between the trenches. On the other hand, in times of peace, when $T_{U}$ is far off, we can begin to make long-range savings or longrange plans for economic development or for feeding the world.

Many of our most violent disagreements in social attitudes, such as the conflict between personal gain and social morality or between short-range and long-range planning, are not disagreements over ultimately desirable goals, or ultimate possible gains, but simply different estimates of the current level of uncertainty and how far $T_{\mathrm{U}}$ is away. Some of our liberal-conservative disputes would be less bitter if both parties could see this and could spend their energies on making better estimates of the uncertainties and the real possibilities of effectiveness. But with our multiple accelerating changes today, clearly it will be a long time before $\tau_{\mathrm{U}}$ can be pushed much farther away than 30 years or so, or before our social understanding of the secondary consequences of our actions will be great enough that we can see the alternatives ahead for more than a generation.

\section{The time-constants of change}

The length of the inertia period, $T_{1}$, is commonly over-estimated in the social sciences. Both conservatives and radicals often hold that things will not change, except by violent revolution. The determinist school seems to be more scientific in holding that there is a dynamic of history, with compelling long-range collective forces, so that with a better understanding of social dynamics and with larger computers, the course of society should be in principle predictable indefinitely into the future, like a railroad track. This view would hold that the choices in the choice period, $T_{\mathrm{C}}$, are only apparent or surface choices which do not change the main thrust; so that the $T_{I}$ period of on-going momentum 
actually extends through the $T_{\mathrm{C}}$ and $T_{\mathrm{U}}$ periods for a generation or more, or perhaps up to 1000 years in the Toynbeean cultural dynamics.

But it can be shown that, at least in self-conscious societies with centralised planning, for many phenomena, $T_{I}$ is in the range of no more than 2 to 10 years. Beyond this, choice becomes increasingly effective, as in the time scales of full economic mobilisation for war (1-2 years), of the change of opinion in the USA to legalise abortions (perhaps about 2 years), of the rise and fall of the Vietnam war ( 5 years), of the creation of the international monetary system of Special Drawing Rights (5 years), or of the race to reach the moon ( 9 years). It will hardly be denied that these are large-scale social acts of conscious choice. The last three are typified by individual acts of leadership which would have been almost impossible to predict very far in advance, by the shrewdest students of social dynamics, or even by the leaders themselves!

A recent study with Karl Deutsch and Dieter Senghaas has shown that half of 62 great achievements or inventions in social science in this century had widespread acceptance or social effects within about 12 years, and that this time appears to be getting shorter since World War II. In each social system, there is an underlying style to these changes, of course-the social 'vehicle', capitalist or communist, is still the same social vehicle. But these styles have changed, too, in the last 20 years - and partly by design, as with the growth of agro-industry, automation, service industries, credit, medical care, universal higher education and government-supported industries, which transform the whole mechanism of social incentives, methods of operation, and class structures.

Of course, there are some social phenomena where change is more sluggish and difficult, like attempts to change the direction of a clumsy ox-cart. World population growth is in this category, for it can hardly be levelled off in less than 10 to 25 years, even if a perfect contraceptive were available tomorrow. This means that world population will almost surely increase in the next 25 years by some 3 billion people, or roughly a factor of 2 . And who can deny that we must bring up all these new children-wanted or unwanted ! - so that they can reach as nearly as possible their full potential as creative citizens of the world? To do this and to make up for our present deficiencies, we must have an increase in world food in this period by roughly a factor of 3 , in world housing by a factor of 4 , in world health care by a factor of 4 , and in world education by a factor of 5 or 10 . We have not yet mobilised our abundance and know-how to meet these massive needs, and in fact it is only in the last year or two that we have begun to realise the full scale of these advancing problems. Nevertheless, analysis and action is beginning to be taken on many fronts, and it seems possible that we can approach many of these goals of world well-being in 20 years if we begin effective action now.

Other social phenomena resistant to change would include 'lock-in' situations, such as Federal bureaus, or the military-industrial complexes of both the USA and Russia, which are themselves tied in to the conflict of lock-ins of the arms race. Nevertheless, some of these problems yield to cost-benefit analysis, as in the proposed restructuring of the US Post Office system. Others can be pushed towards re-adjustment by the growth of world interdependence, as well as by abstract analysis of the barriers to change in such systems and 
the damage they do to the larger system of which they are a part. The lock-ins slow up change-like wagons with fixed wheels-but they can themselves be changed, usually suddenly, when the pressure for a new direction gets great enough.

It would appear that the $T_{\mathrm{C}}$ period, when our present social choices create fairly predictable changes, might run to about the year 1990 or 2000 . The period beyond that almost surely is in our $\mathcal{T}_{U}$ interval, because of our great uncertainties as to the consequences of our present rapid ferment and change. By that time the world might have been transformed to any of several extreme forms, such as a post-nuclear desert; or a world dictatorship by nuclear blackmail; or a 1984 type of permanent war, sustaining competing dictatorships; or just possibly a group of open pluralist democracies in a world of growing abundance for all. The probability of the latter is terribly small. It will only be by enormous efforts of social invention and action in the next few months and years that the other dangers can be averted and that it can be achieved at all. Not until it is clear whether we are moving in that direction will it be clear whether we can predict or even prophesy the shape of the year 2000.

\section{The design of change}

We can see these problems better if we enlarge our simile, going beyond the problems of the motion and guidance of a single vehicle, to the problems of overseeing the progress and the collective guidance of a whole wagon train exploring new country. As we shall see, we need to explore the analogies to the problem of looking over the country ahead, sending out scouts, and mapping the alternative routes; and the analogies of making sure the vehicles are designed well and are working properly and are responsive to the steering mechanism, and have rules of the road so they do not get in each others' way. We will need especially to explore the role of technical experts (scouts, repairmen, advisors) and managers (captains, quarter-masters, drivers) and the process of collective decision-making and agreement by all the parties.

For this purpose, the wagon train analogy is better than the strongly authoritarian analogy of a ship, where the ignorant passengers have no choice but to trust their safety to the authority of the experienced captain and his crew. The role of managerial elites is diminishing today; and with increased education there is an increased demand by all individuals and groups, as with the families in a wagon train, for direct participation in all decisions affecting their destiny.

How a large society of men could set up a structure that would enable them to solve their decisions collectively without some royal or authoritarian hierarchy was the problem first solved explicitly by the Federalists in 1789 . They felt that for the first time they were putting into practice theoretical and experimentally tested principles of social design. They said, "It seems to have been reserved to the people of this generation to decide the important question, whether societies of men are really capable or not, of establishing good government from reflection and choice, or whether they are forever destined to depend, for their political constitutions, on accident and force".

The Marxists later criticised this 18th century attempt at social design on the grounds that it favoured a privileged economic group, and they tried to 
make a new social design that would fulfil instead the goals of the class struggle and permit the workers or the majority of mankind to participate in the fruits of production. On the other hand, such technical features of social design as feedback correction ('checks and balances') to correct bureaucratic abuses and inadequacies, or allowance for diversity of tastes and styles of life, or the provision of incentives for improved systems organisation, or the adjustment of social structure to take account of change, seem to have been given inadequate attention in Marxist formulations and practice.

Today it would appear that we could make social designs and world structures greatly improved over any of these previous models. We have a new range of technological powers and abundance and a new understanding of technological change. We have a new knowledge of feedback stabilisation, cybernetic goal-seeking, and hierarchical decision-systems. And we have a new knowledge of the biological and psychological bases of individual and group behaviour. With our new abundance, it is possible to make new designs-systems designs for the benefit of the whole society-that do not need to favour any one group or class in society over any other one. It is possible to make designs that will satisfy both urban and farm, suburb and central city, workers and intellectuals, managers and consumers, blacks and whites, males and females-designs that can permit and encourage pluralism and diversity of tastes and life styles, with abundance for every group. Some societies today are closer to this kind of world than others are, but even the best of them have grave misdirection of energies, unresponsive administrations, oppressed groups, and great blights and crises; and the world in its overall structure is still very far from such a goal.

Can we make a successful transition from where we are, to this kind of improved future design for everyone? Can we do it without any break in the social continuity of food and goods and services that we need to sustain us all? It is almost certainly possible, but we can achieve it only if we understand and work out in detail what kind of new designs we want, both for our societies and for the world, and if we understand the processes of change and institutional restructuring that can take us from here to there. This kind of improved social design for the future of mankind must be begun now if we are not to be destroyed by the crises of the next few years. It will require the very best scientific and analytical, administrative and political, legal and philosophical talents we have. It can go, and it must go, in its competence and detail of design and in its general satisfaction of human needs, far beyond any social design we have ever had in the past.

\section{Map-making for the future}

When we look more generally at the if-then formulation of history, we see that what we are talking about is a map of all the possible directions of change. 'If we do $a$, then we reach $A$ in 30 years', specifies one path on the map. 'If we do $b$, then we reach $B$ ', specifies another. All the alternative possibilities together could be laid out on a real map, in our $T_{C}$ range of times (or distances) although it might have to be a multi-dimensional map to fit the multi-dimensional character of real social decisions and actions.

As soon as we recognise the map analogy, we see how over-simplified is any 
single if-then statement. A complete map is not one-choice-one-goal, like firing a gun at a distant target. Rather it is a set of roads or paths of least energy, which may not be straight, because they have to avoid mountain barriers and precipices. And these roads have no single goal, but march on and on across the map, with every point a decision-point for the drivers in terms of direction and speed through the next section, and with occasional intersections where radical new directions can be chosen if desired. Sometimes we may have to go up in order to go down, or go around in order to go forward. Such subtleties are probably beyond most of our present social prophecies, which are still in the linear-forecasting stage, but they will come with increasing knowledge.

Of course, our map will be very uncertain and full of Terrae Incognitae in regions of social space we have never explored, like those before us at the present time. We can only see the future, so to speak, from a high point near the trail, when what we really need is an exact aerial survey of the various paths ahead. We must develop these improved surveys, and quickly; but since we are travelling on and cannot wait, at any given instant we can only choose what seems the best route at that time while keeping careful watch to see that we do not pass some point of no return or get trapped in a narrow valley from which there is no way out. Ancient Egypt, with the burden of its royal-tomb economics, was stuck in such a social valley for 2000 years. Many scenarios today could lead to a world dictatorship or a new Dark Ages with much the same result for us.

Of course, a good map of our future would not be a 'flat' map showing completed roads, but rather a 'contour map' of the terrain, across which we make our own road as we go, like the wagon train. The heights and depths on the contour map are fairly exact metaphors for the social costs and consequences of any given path of travel. The regions with high social costs have to be avoided in planning the future, because society generally tends to 'go downhill' or in the direction of least resistance except when it is carried into a high-cost region, so to speak, by its own momentum.

Society may be able to get over a small barrier, such as organisational problems or vested interests, by such mechanisms as capital investment or national re-allocation, provided there is promise of a downhill 'gain' on the other side. A hilly path, if short, has frequently been preferred to a 'more natural' longer path in conscious human decision-making, because of our determination to make visible progress in the foreseeable future in satisfying human needs and aspirations.

Probably the step-by-step mapping of the costs and consequences of different paths of social change will become one of the main contributions of 'prophecy' or 'futurology' to large-scale human affairs. All the forecasting techniques of industry, with product assessment and market research, will need to be applied on a far larger scale. It is not 'advice' we want, so much as an impartial mapping of costs and consequences. This is one of the most valuable things that parents, teachers, psychiatrists, economic counsellors, or other intellectual elites have to offer to the young or to other sectors of society. We do not want to be told or co-erced or manipulated into doing some particular thing-even if it is supposed to be for our own good-so much as we want to know as accurately 
as possible what the consequences are of the different alternatives, so we can make the decision for ourselves. This nourishes our sense of dignity and responsibility and helps the growth of knowledge and freedom that we need to become complete men and independent citizens. Perhaps we can add important additional facts to the map that direct persuasion would never have uncovered! So the teacher who offers, not advice, but a map of all the consequences, has already started to wean the student and to make him a chooser and teacher himself. An accurate map is basically non-political, or can be made so, so that it spreads by desire to those who want it, affecting all the decisions of society much faster than the best self-interested attempts at persuasion.

\section{Maps as conflict reducers}

Improvements in our maps of costs and consequences also can often help in reducing disputes and differences. Someone has said that men do not differ in their goals so much as in their choice of competing heuristics or paths towards reaching the goals. A better calculus of costs can help to straighten out misinformation or false clichés, and make one strategy or the other much more convincing. Trustworthy maps reassured the families in the wagon trains and kept them from splitting up. Probably the same will be true for many social groups today facing disputed social decisions.

Better maps may not only bridge divergent pictures of reality but may even do something towards bridging divergent self-interests. If one route can be shown to be clearly more promising than another in terms of total social costs in reaching a generally agreed-upon goal, then that total social advantage can be partly used to give compensating personal advantages to groups whose interests are damaged by taking that route. Thus we compensate landowners displaced by a highway, or workers displaced by automation. It is only when the total advantage is uncertain that the disputes rage on. Much wider use of this principle of pre-assessment and compensation would help many of our needed social changes to go faster and with less disruption.

Conflicts of values or general life-styles for whole communities are harder to deal with, because a culture can scarcely be both communal and capitalist, both tribal and nuclear, or both existentialist and Puritan at the same time. Such conflicts can only be resolved in a society of space and abundance, which does not need to co-opt all of its members into any particular kind of consumerism or housing or work-pattern. In such an economy, we can see that Diversity will be one of the most valuable directions on the map of change. (In a multi-dimensional map of social 'phase-space', Diversity would be represented by all the regions 'away from the axes', where there are components from many different axes of variation; while Uniformity would be represented by the much narrower regions along one axis or another, with no components in other directions permitted.) Such a society would begin to be a society of tolerance and experiment, in which different personality types and different cultural traditions have a chance to be protected in trying out their preferred ways of life on a limited scale, although they might not be imitated by the rest of society as their costs and values become more apparent.

Why should we say that men are born equal or unequal? The truth is rather 
that all men are born incommensurable. They live their lives on different axes. The encouragement of experiments in diversity would be a great aid in reducing our attempts to make ourselves one-dimensional and in reducing our present divisive conflicts over goals and our coercion of minorities by majorities.

It is worth noting how far Western society today has gone in the creation and tolerance of this kind of diversity. In the USA today, in spite of all its continuing problems of mutual adjustment of different groups, there is probably more diversity accepted in such things as architecture, jobs, dress, books, films, records, music, poetry, and life-styles than in any society in history. It would be easier for many nations to accept the idea of One World if they saw it as both having and encouraging this kind of variety and self-expression for every cultural tradition.

\section{The role of technical elites}

Probably it will always be technical elites who have to perform the 'look-out' operations and make the maps. But they are also needed to keep up with the overall preparations for the trip, checking the state of the vehicle, making needed repairs and improvements, and managing the carrying-out of the group's decisions after they are made. The 'vehicles' in our analogy are the social institutions involved in change, their organisational leadership and responsiveness and stability. The 'repairs and improvements' are the small 'seed operations', such as needed research and development, which can greatly change the organisational stability and responsiveness to change.

What needs particular attention is the steering mechanism-our collective decision-making mechanism for collective social problems. Technical behavioural science is badly needed, to show us how to debate and reach decisions more quickly and satisfactorily in groups and parliaments, how to make use of needed technical advice, and how to tolerate diversity and provide mechanisms and incentives for conflict-resolution between dissenting parties. We may need new methods of information-handling and information reduction, new types of social contract in co-operating groups, and new parliamentary decision-rules.

Specialists are also needed for carrying out technical decisions, and for mediating the social processes and the feedback channels of the system to be sure they are working in the directions of change intended by the group. This involves continuous monitoring and information-sharing, with expediters and ombudsmen to keep the wheels greased on the social vehicle and to look out for malfunction or 'overheating'. This role goes over continuously into the larger goal-assessment and direction-assessment and progress-assessment and expediting for the whole on-going process of change.

Will the specialists get out of hand and become dictators? Not in a higheducation high-information society where common sense and personal concern and widespread know-how can monitor the monitors. Not if we design our rules of collective decision-making so as to assure a rotation of technical elites and equal technical help to the 'loyal opposition', and to permit counter-analyses and counter-plans when any group feels it needs them to prevent preemption of humane alternatives by technocratic arrogance or stupidity. 


\section{Collective decision-making}

After the technical elites have made their maps, and provided their information and inventions and assessments and advice, it is still the participants in our planetary wagon train who must make the final choices of their future direction or directions.

Several features stand out as requirements for satisfactory group decisionmaking in the world ahead. The first is that all social decisions from now on must be participatory. Every individual or sub-group must have as large a share as is practically attainable in the decisions that affect his destiny. Any society that violates this rule, as by subjecting individuals to discrimination or injustice that its affluence and education could avoid, or by subjecting them to administrative decisions in which they or their representatives have had no responsive part, is in grave danger of riot and breakdown. This may or may not lead to the counter-response of a police state, but whether it does or not, the cost in economic and social abundance from such a malfunctioning system is enormous. Equality costs very little compared to these costs or compared to the enormous pay-offs for everybody from a well-functioning society whose human beings feel that their needs and complaints have adequate and equal satisfaction and prompt redress.

The second requirement for satisfactory group decision-making is general recognition of and education about the non-zero-sum nature of all our social decisions. We are now involved with each other in a total system where we will all win together in effective system-operation, or all lose together in malfunction and breakdown. The total result depends on whether we offer each other tolerance or hatred, reward or punishment, trust or distrust, independence of coercion. The collective advantages in a satisfactorily operating social and political system, with its present blocks and malfunctions removed, could give all the world an abundance almost beyond imagining. It would be enough to make the present poor as well as the present rich far richer in goods and personal satisfactions than anyone is now, in our present conflicting and maldirected social groups.

\section{The sense of historical process}

A third requirement for collective decision is a general understanding of the historical process of change. Everyone involved in debating the collective future needs to realise that, as we have shown here, change cannot be instantaneous and is rarely smooth. There will be advances and retreats as existing feedbacks come into play to resist encroachment on their domains. Locked-in systems will resist change until they are restructured. There will be successive stages of education of those involved in change. Sometimes old or growing abuses can be wiped out at the stroke of a pen, but at other times they are ingrained deep in personal habit patterns or in slow patterns of committee work or legal rules or large-scale organisation or economics that have to be attacked indirectly.

A sense of historical process helps us maintain our patience as well as our pressure. A lost battle or an important crisis, like the California oil spills, may 
dramatise the human problem; and if we are prepared to make use of it, it can be an important step in re-educating the public for the next step. Grises, if not completely catastrophic, can be incentives to faster action, as well as useful signals of the imminence of more dangerous crises and of the level of needs and demands that we still have to satisfy and the distance that we still have to go.

Change can also be accomplished more easily and successfully if all those involved can be kept aware of the goals and the distance to them, and of whether the mechanisms of change are on schedule as the wagon train of history swings around to new directions. In particular, the sense of process helps us keep in mind that no new direction is ever final. As with any vehicle, the direction must be continuously corrected and corrected again to adjust for the bumps in the road or the errors in the last correction, or to swerve towards an easier and swifter route even though it is not the straightest.

The reason is that the directing of change is a feedback system, a process of successive approximations. First solutions, like early motor cars or early detergents, are frequently crude, with unforeseen side effects, and they require successive later inventions to improve on them or to correct the first-order side effects, the second-order side effects, and so on. The new technology devised for a new age will rarely seem as easy or familiar or rewarding at first as the age-old practices of farm and kitchen-which were themselves once new inventions. So social therapy or change, like individual therapy, must not be thought of as a one-shot affair but as a continuous process of 'working through', with the consequences from one step leading to a new evaluation or awareness, which then makes possible the moving on to the next step, in a process that never ends.

Nevertheless, the sense of process must not deprive us of the sense of urgency. We must never forget that men who have been handicapped in reaching the full potentiality that the world should first have offered them, will want to see visible progress and real hope for getting their problems solved at maximum speed, so they will not be driven to despair and destruction. While we recognise the long run historical process, we must still find an emergency mechanism to feed the starving family today, not a year from now.

\section{The need for tension}

It would also help us if we all recognised that the process of change necessarily involves tension in the society. The tension occurs because there is a personal and a social cost in changing our institutions, just as there is a personal and social cost in letting them go unchanged. The only way to achieve the minimum cost and the least disruptive speed of change is to let the debate go on between those who are more hurt by the speed of change and those who are more hurt by its slowness.

More fundamentally, the creation of change requires prophets and leaders who see the social ills and the new goals and the practical steps towards them. They are the ones who produce the creative tensions that pull the wagon of history. But these prophets must not go unchallenged. Prophets may be wrong, and their insights damaging to large groups or ways of life. Real conservatives, who see the danger in the new ways, need to make their counterclaims for 
holding on the old, or for modifying or slowing down the new proposals so that older people or institutions with their own values will have more time to adapt or to protect themselves.

As long as this tension of ideas and values does not reach the breaking point, it is a necessary part of a healthy society and healthy progress, and is something to be applauded, even in one's opponents. The prophet's case, if it is a good one, is not damaged but helped by the pressure on him to make it convincing, or to prove its necessity to those who feel the need to reconcile it with older values. And if he cannot prove it to the satisfaction of others, everyone is the gainer for having settled it by discussion and analysis instead of by expensive trial. These debates will often lead to useful pilot studies to clear up the uncertainties, like scouts that go out ahead to survey the terrain.

It is not good if the social motor can pull the social vehicle in new directions with only trivial pressures; it must exert a serious stress on it if the existing ways that are to be changed have any ongoing value at all. (Some kind of stress or cognitive dissonance is the pre-condition for learning, as the psychologists say.) This means we need a society that responds, but not too easily; because we also need one that is careful to conserve whatever values and effectiveness were built in earlier. So the vehicle needs to be sturdy, and must not have such flimsy steering, so to speak, that it is blown off course by every wind or wanders all over the road with no continuity or stability in the direction that has been chosen.

This need for tension as well as for resistance to tension must not be viewed in our usual glib moralising way in terms of 'good' and 'evil'. The solutions we must look for are total systems-solutions that offer 'goods' to both the conservative and the prophet, both to this man's need for continuity and that man's need for urgent change. The difference between a successful system and a less successful system or combination of competing sub-systems is not an opposition between positive and negative like 'good' and 'evil', but rather like the difference between two positives, like 'good' and 'less good' or richer and poorer, or higher and lower temperatures.

From the 'systems' point of view, every man or organism, by the fact of being a viable organism, a living system, is always pursuing some kind of good for his own system, even if it is only a personal or short-term good, or a false good perhaps representing some past reinforcement or reward that is now mistakenly pursued. No man is wicked to himself; what the small man is pursuing is his own small version of the good, even if he regrets it afterwards; and it is rare that our old religious notions of good-and-evil confrontation or punishment can help him to enlarge that version. It would be more effective if we could always see these smaller or short-range goods of the individual or the group or nation as being, not contradicted, but greatly enlarged for every single one as soon as we begin to pursue the larger long-range goods of our human world system as a whole. The good of Man does not conflict with the goods of men, but can enlarge them and can provide them more easily and abundantly than any men can provide by themselves in smaller isolated or competing groups.

So, we should perceive the 'wicked' reactionary, or the 'wicked' anarchist as rather pursuing his own version of the good, or acting out his own doubt and hopelessness that larger goods can ever be achieved. Those of us who want 
more satisfying social systems for the world would have more persuasiveness and more effectiveness in producing change if we could remember this. Instead of damning these errors as evil, we should learn to recognise that our worst opponents are only holding smaller versions-or perhaps only different versions - of idealism and the good. By accepting the creative part of their vision, we could begin to show them, and ourselves, how that vision can actually be encompassed and enlarged by mutual support and mutual change.

\section{The profit of Utopias}

These considerations on the total value of better overall human design lead to two useful theorems on the motive force for social change. These theorems show how our collective decision and action can actually be powered in the needed directions. The first theorem is that Utopias will be enormously profitable for everybody, in economic as well as human terms. What we mean by a 'future good' is some real hope for ourselves or our community or our worldsome hope tangible enough and probable enough to be worth working for, which means worth investing in, in time or effort or money. Why else do men work at all, except to reach such anticipated goods? We see that the gap between what is and what might be is the only real source of power in the world. Megawatts of technical power and organisation will be turned off if we do not think they are bringing us closer to the good that 'might be'.

But if improvements are worth working for, it means that we expect them to bring a human or economic return that will more than 'pay for' the effort. Why then do we not pursue larger Utopias more often? The reason is that we do not see how to get there, or we have a low estimate of success in an untried enterprise in an uncertain world, so that we fear we will lose our effort and be taken for fools. Better maps of the costs and consequences can reduce this uncertainty and make the investment of effort and money in new directions more attractive, as several nations have shown by their investments in housing, medical care, education and many other constructive areas. Does the control of pollution cost too much? No, it actually saves money, as can be shown immediately by a better social accounting, that measures, say, the domestic savings in reducing dirt and lung disease, or the total public and private savings from re-cycling and the better systems-handling of pollutants.

A good society is a society with its blocks and malfunctions and inequities removed, so that every transaction and operation becomes smoother and more profitable. Men will enjoy and support such a society more and will be better educated and supported by it than they are at present. Can any believer in the effectiveness of well-integrated organisms doubt that such a society would be immensely richer and more successful than ours?

In the economic calculation, the future profits that a better system could give us will need to be 'discounted', of course, like any futures that take investments away from present pleasures. But this discounting, or interest to be paid, simply means that the business of planning and working for the future can be made part of the ordinary economic process, and that alternative goods and strategies and uncertainties can be balanced against each other by familiar economic mechanisms. Banks invest in the development of dams and housing. 
From these, it is not such a far step to realise that we can all invest in the development of the world, and so bring it into being.

The fact that Utopias are profitable means that most of the barriers to reaching them can be surmounted by analysis and design, because we can find investment money for doing the analysis and work to get over the barriers, as long as there is a clear gain on the other side. It is like a social siphon for going over hills; or like a social enzyme, to use the biochemical analogy, to get around or tunnel through barriers as long as the overall direction is generally 'downhill'. The problem of barriers to needed change, whether they are barriers of organisational complexity, or vested interests, or group conflicts, is therefore generally solvable if some 'social entrepreneur'-some individual or group-will analyse the ultimate human and economic profits and the local difficulties, and will then apply that investment potential to pay-offs that will help get around the bottlenecks and the human resistances that stand in the way.

\section{Powering change}

This leads to the second theorem, which is that the profitability of Utopias can be transformed into human and economic profit for every individual or group involved in the change. In fact, strangely enough, the poorer the group is, the greater is the benefit or pay-off from a restructuring of society to give them more. The reason why downtrodden and underprivileged groups are willing to make such an enormous personal investment in protest and violence is not only because there is nothing to lose but because there is everything to gain. Any society that does not realise this fact of Utopian power, and lets inequities grow without redress, is in the gravest peril because of the violent transforming potential of the difference between 'what is' and 'what might be'. The ghettoes will be heard, and the 'third world' will be heard, by hijacking and assassination if not by armies, because they are the dry tinder for 'the fire next time' if their demands for humanity and hope and abundance are not met. The world is now too dangerous for anything less than Utopia.

But the positive side of this theorem is that analysis in advance can find investments and pay-offs sufficient to move the most obstructionist individuals or institutions. The ghetto child, if well-nourished and well-educated, begins to be a fully contributing citizen who will pay back in taxes alone far more than the cost of his food and education. There is profit enough for the Rajahs and the steel owners to be paid off, for the Post Office unions to be offered real raises, and for the oil-spill conservatives and the abortion opponents to be shown the political error of their ways. Sometimes these pay-offs seem like rewards for obstructionism, but this is often the cheapest and simplest way to remove the blocks to needed change. It is not entirely inequitable to pay a small midwife fee to the old system to let the new world be born.

These mechanisms of real profit in creating Utopia mean that we have an additional way of healing disputes and obstructions in our collective decision process. These theorems might even permit helpful 'meta-agreements' on the ground rules of the debate-like the meta-agreements between opponents in Parliament, who may agree to always speak in turn even if they violently disagree on everything else. The meta-agreements we could establish today 
might include, first, a general recognition by every party of the non-zero-sum character of our world, a recognition that we will all win or all lose together depending on whether we build up mutual satisfaction or mutual hostility. This means a recognition of the profitability of Utopia, and of the possibility of an adequate adjustment for those who might be hurt. A second meta-agreement might be an agreement to tolerate and support diversity, including even obnoxious opinions and life styles, for the sake of pluralism and to encourage the exploration of new regions of the social map, even those that may not be satisfying in the end. A third meta-agreement might include a kind of moral imperative in all our attitudes, whether Establishment or anarchist, or rich or poor, that even if we differ on details, each of us will agree to keep searching and working for larger and more long-range social goods for everyone on the planet.

These thoughts suggest that it might be possible to arrive at a generally accepted and coherent picture of the process of social design and change. The process of shaping history is not a predetermined physical mechanism but an on-going cybernetic process, powered by practical Utopian constructs, with large-scale collective decision and action which have already been shown to be able to reach particular goals in times that are surprisingly short. For creating a more stable and more rewarding society, the human and economic profits are great and the investment for getting over the barriers is economically feasible. The mechanisms and pay-offs for reduction of conflict and for the increase of large-scale and more successful systems organisation are numerous. In short, the future lies open to our collective design and action.

The problem is only to begin. 